\title{
Toxicity of selenium nanoparticles on the development of rat neonates
}

\author{
Lamiaa E. M. Deef ${ }^{1}$, MaieI. El Gammal ${ }^{2}$ and Khaled Fathy ${ }^{3}$ \\ ${ }^{1}$ Zoology Department, Faculty of Science, Damietta University, Egypt \\ ${ }^{2}$ Environmental Sciences Department, Faculty of Science, DamiettaUniversity, Egypt \\ $3^{3 *}$ Electron Microscope Unit, Mansoura University, Mansoura, Egypt \\ *Email: fathy.khaled202@gmail.com.
}

\begin{abstract}
The present study aims to investigate the impact of selenium on the morphological, biochemical and ultrastructural changes in the testes, ovaries and livers of mothers rats and their 14 days old age neonates by transmission electron microscopy. Female rats were dosed orally with distal water and $0.5,1.7$, and $6.0 \mathrm{mg} \mathrm{Se} / \mathrm{kg}$ bw/day as $(10-45) \mathrm{nm}$ SeNPs, for 14 days old age neonates. At doses of 1.7 and $6.0 \mathrm{mg} \mathrm{Se} / \mathrm{kg}$ bw/day, a lowering in body weight gain was recorded as compared with the control group. Decrease in Glutathione peroxidase (GPX) of moderate dose (MD) and high dose (HD) groups was explained as due to increase reactive oxygen species in body tissues. There was increase in oxidative status (GPX) of Low Dose (LD) comparing to control group. There were no histological changes in the liver, ovary and testes of the investigated neonates at LD, MD and HD groups.

The toxicity of Se NPs on oxidation status and ultrastructure of ovaries and testes did not occur at low levels $0.5 \mathrm{mg} \mathrm{Se} / \mathrm{kg}$ but appear with degrees of changes at high level Se NPs(1.7 $6.0 \mathrm{mg} \mathrm{Se} / \mathrm{kg}$ ). The present results indicated that Se NPs were not toxic at supra-nutritional levels and can induce a positive effect on both neonate rats health at a dose of $0.5 \mu \mathrm{g} \mathrm{Se} / \mathrm{kg}$-bw and in mother rats growth, whereas the chronic toxicity will be induced by more than $1.7 \mu \mathrm{g} \mathrm{Se} / \mathrm{kg}-\mathrm{bw}$.
\end{abstract}

Key words: Selenium nanoparticles, ultrastructure, ovary, liver, neonates, rats.

\section{INTRODUCTION}

Selenium is commonly known as an antioxidant due to its presence as selenocysteine in selenoprotein that can catalyze reduction of disulfide bonds in proteins and peptides. One class of its compound is a main suppressor of cell growth with definite tumor specificity (Misra et al., 2015).Selenium nanoparticles SeNPs form is considered as medical factor due to its low therapeutic effect, bioavailability and less toxicity characters. Chemical synthesizing of selenium nanoparticle has been reported as a drug carrier and tumor therapeutic element (Vekariya et al., 2012).

Selenium has important effect on the reduction of oxidative stress reducing the risk of cell toxicity. it has anti-microbial role, anti-fungal activity, it possesses potential as a cancer chemo preventive agent and its immune stimulatory effect was confirmed (Hosnedlova et al., 2018). The amount of selenium absorbed by human body can be evaluated by its level in serum, urine, hair or nails and its contents measured in serum with normal range between 75 and $140 \mu \mathrm{g} / \mathrm{L}$ (Morris et al., 2013).

Effects of selenium are dose dependent were its high and low doses linked with pathological aspects. Selenium high dose are stimulate the toxicity in both humans and animals. In rats, the low dose of selenium protects them against other selenium compounds lethal effect (Ostadalova, 2012). 


\section{Lamiaa E. M. Deef et al.}

It is necessary to take care of Se toxicity because of its daily intake from food and water. It can be cumulative in the food chain, pollution by selenium mostly in the aqueous environment; can cause selenium poisoning (Wang et al., 2017). High blood concentration of $\mathrm{Se}$ can cause selenosis disorder, a syndrome characterized by gastrointestinal symptoms, white blotchy nails, hair loss, garlic breath odor (due to methylated Se), irritability, fatigue, and peripheral neuropathy (Koller et al., 1986). Nogueira et al. (2011) reported that farming animals poisoning (selenosis) caused by the ingestion of the Se element coming from its accumulating plants in reach Se soils.

Reproductive toxicity displayed as the toxic of a substance on the reproductive status of an organism, development of its neonates, and it is adverse effects on fertility and sexual function of adult females and males. As well as developmental toxicity in the offspring means adverse effects induced during pregnancy, or as a result of parental exposure, manifested at any point in the life span of the organism. However, in most of these reports the effect of selenium on the structure of internal organs of both mothers rats and its neonates recived a little attension particulary with respect to histological and ultrastructural changes. Therfore, the aim of the present work was designed to evaluate the morphological, biochemical and ultrastructural changes in the testes, ovaries and livers of mothers rats and their 14 days old age neonates by transmission electron microscopy.

\section{MATERIALS AND METHODS}

\section{Experimental animals:}

The present experimental study was carried out on 40 white albino rats (32 female and 8 males) (Sprague Dawley) weighted 150-200 g obtained from Medical Experimental Research Center MERC (Mansoura University, Faculty of Medicine).

\section{For breeding:}

Females caged together with male of proven fertility with (4:1 ratio) overnight under controlled environmental conditions of temperature, humidity and light. Pregnancy was determined next morning by the presence of spermatozoa in the vaginal smears and was considered as day zero of gestation.

\subsection{Experimental design:}

The Route of administration to females only was orally via gastric tube (Gavage), and the time of Nano selenium administration was scheduled from zero day of gestation, daily until day $13^{\text {th }}$ of lactation for the adult pregnant females. Water and food were supplied ad libitum during all the experiment:

\subsection{Experimental groups:}

Pregnant rats $(n=32)$ were randomly divided into equal four groups ( 8 pregnant female rats in each group). The experimental groups were as follows:

- Control Group (NG): received distilled water only.

- Low Dose Group (LD): treated daily with $0.5 \mathrm{mg} / \mathrm{kg}$.bw of Se NPs.

- Moderate Dose Group (MD): treated daily with $1.7 \mathrm{mg} / \mathrm{kg} . \mathrm{bw}$ of Se NPs.

- High Dose Group (HD): treated daily with $6.0 \mathrm{mg} / \mathrm{kg} . \mathrm{bw}$ of Se NPs.

Doses were selected according to He et al. (2014). All mother rats and their 14 days old age neonates were sacrificed at $14^{\text {th }}$ of lactation.

\section{a. Morphological Study:}

A daily weight of the pregnant females was record throughout the whole gestation period. The daily weighted of neonates, fetal mortality rates still birth and living fetuses were recorded. Malformations were also recorded. 


\section{Toxicity of selenium nanoparticles on the development of rat neonates}

\section{b. Biochemical Analysis:}

Alanine transaminase (ALT) and Aspartate aminotransferase (AST) were determined using Spectrum Diagnostics kits (30 Obour City - Cairo, Egypt). Where ALT kit use End point method at wave length 530-550 nm (ECCLS ., 1989), but AST use Kinetic method at wave length 334 - $365 \mathrm{~nm}$ (Young, 1990).

Glutathione Peroxidase (GPX) was determined using diagnostic kit from Bio diagnostic company (29 El-Tahrer St. Dokki- Giza - Egypt). Its principle is that GPX catalyzing the reduction of $\mathrm{H} 2 \mathrm{O} 2$ to water and organic peroxides, the measurement at absorbance of wave length 340 nm (Paglia et al., 1967).

\section{c. Histopathological examination:}

1. Light Microscope examination

Immediately after scarifying neonates of the four groups by decapitation, Liver, ovaries and testes of neonates of each group were fixed in $10 \%$ formal saline for at least 24 hours and dehydration in ascending grades of ethyl alcohol. Specimens were cleared in xylene, and then embedded in

paraffin at 56 degree in hot air oven for twenty four hours. Paraffin wax tissue were

Table 1: Changes in weight gain of pregnant rats during gestation period from the $5^{\text {th }}$ and the $20^{\text {th }}$ day of gestation.

\begin{tabular}{|c||c||}
\hline Group & $\begin{array}{c}\text { Average increase in weight (g) between } \\
\mathbf{5}^{\text {th }} \text { and } \mathbf{2 0}^{\text {th }} \text { day of gestation }\end{array}$ \\
\hline \hline NG & $53.10 \pm 3.73$ \\
\hline \hline LD & $56.20 \pm 2.77$ \\
\hline \hline MD & $48.30 \pm 2.91$ \\
\hline \hline HD & $39.07 \pm 1.74 * * a, b, c$ \\
\hline
\end{tabular}

Each value represented the Mean \pm SD. Significant at $\mathrm{P}<0.05$ prepared for sectioning at 4 microns thickness with microtome, and then stained by hematoxylin and eosin (Banchroft et al., 1996).

\section{Transmission Electron microscope examination}

Ovary, testes samples of neonates were fixed in $4 \%$ formaldehyde and $1 \%$ glutaraldehyde fixation, dehydrated in ascending ethyl alcohol, and then embedded in araldite resin. Sectioning to thickness of 0.5-1.0 um and then stained with toluidine blue stain for 2-5 min. Then sections observed under microscope for precise location to cut for ultrathin sections at 60-90 $\mathrm{nm}$ and collect sections onto grids(Cheville et al., 2014).

\section{Morphological Changes}

\subsection{Effect of Selenium Nanoparticles}

(Se NPs ) on body weight

The weight gain of LD pregnant rats was slightly increased, while in MD group, the weight of mothers was decreased comparing to the control group. In HD group, mother's weight was significantly decreased comparing to the control group (Table 1 and Fig. 1). 
Lamiaa E. M. Deef $e t a l$.

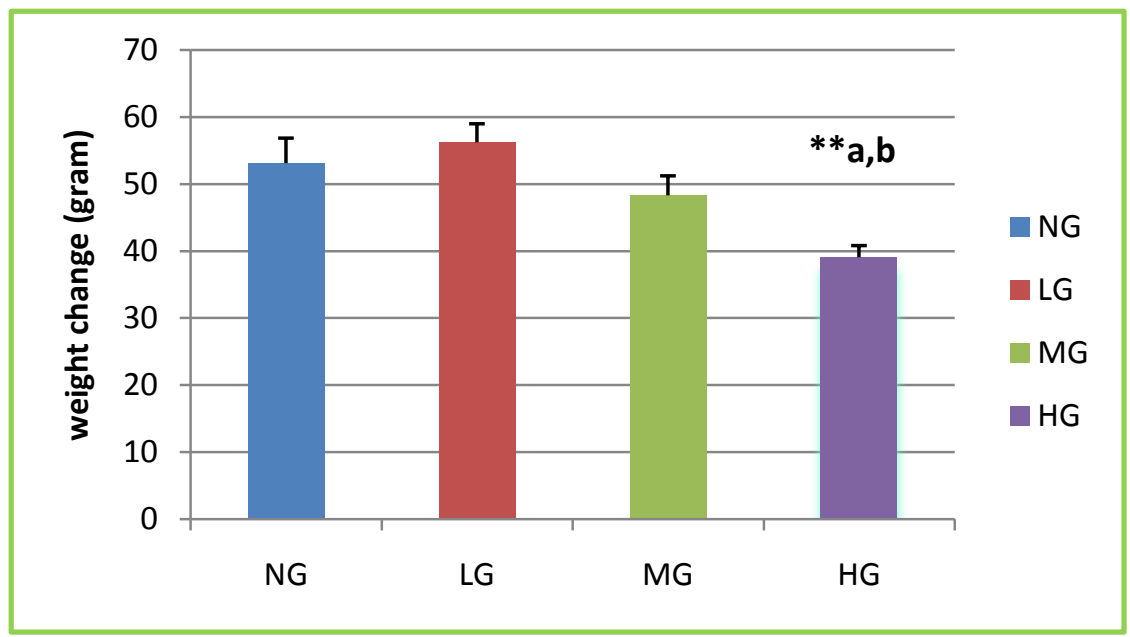

Fig. 1: Changes in weight gain of pregnant rats from the $5^{\text {th }}$ to the $20^{\text {th }}$ day of gestation.

In the current study, the obtained results of the body weight were in accordance with Flaws et al., (2016), who reported that there was no effect of Se status on growth of mice or rats fed 0 to $0.2 \mu \mathrm{g}$ $\mathrm{Se} / \mathrm{g}$ diet, however, rats fed $5 \mu \mathrm{g} \mathrm{Se} / \mathrm{g}$ diet showed a $23 \%$ decrease in growth indicating Se toxicity.

\subsection{Effect of Se NPs on Fetal Mortality}

As seen in Table (2), no fetal mortality was found in control group $(0 \%)$, while there was 6 dead neonates $(5.6 \%)$ in the LD group, 13 (16.25) in MD group and $16(28.6 \%)$ in HD group, whereas, there was a significant reduced in survivability of neonates comparing to control (Fig. 2).

Table 2: Effect of Selenium Nanoparticles (\%) on Fetal Mortality from Zero day of Gestation to $14^{\text {the }}$ day of Lactation

\begin{tabular}{|c|c||c||c|c|c|}
\hline Group & $\begin{array}{c}\text { No. of rats give } \\
\text { birth }\end{array}$ & $\begin{array}{c}\text { Total no. of } \\
\text { neonates }\end{array}$ & $\begin{array}{c}\text { No. of dead } \\
\text { neonates }\end{array}$ & $\begin{array}{c}\text { Percentage of live } \\
\text { neonates }\end{array}$ & T. Mortality rates \% \\
\hline \hline NG & 9 & 72 & 0 & $100 \%$ & $0 \%$ \\
\hline LD & 11 & 88 & 5 & $93.9 \%$ & $5.6 \%$ \\
\hline \hline MD & 10 & 80 & 13 & $83.75 \%$ & $16.25 \%$ \\
\hline HD & 7 & 56 & 16 & $71.4 \%$ & $28.6 \%$ \\
\hline
\end{tabular}

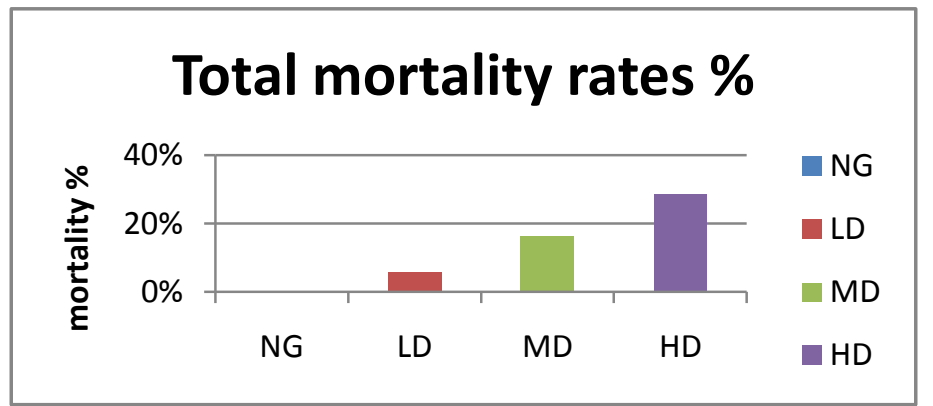

Fig.2: Fetal Mortality (\%), from Zero Day of gestation to $14^{\text {the }}$ day of Lactation 
The result of the fetal mortality of neonates was similar to that of Hosnedlova et al. (2018) who displayed that concentrations of $8.0 \mathrm{mg} \mathrm{Se} / \mathrm{kg}$ caused an increase in mortality of rates in comparable to controls, while $4 \mathrm{mg} \mathrm{Se} / \mathrm{kg}$ impaired growth and reduced survivability, and the weight gain was equivalent for treated and non-treated controls. However, a lower dose of $1.2 \mathrm{mg} \mathrm{Se} / \mathrm{kg}$ body weight produced $100 \%$ mortality in five days. These results may be due to varies in the doses of selenium.

\subsection{Effect of Se NPs on body weight of neonates growth}

There was no significant change in the body weight of Neonates at $1^{\text {st }}$ day of treated groups comparing with control group, however, the body weight of neonates at the $7^{\text {th }}$ and $14^{\text {th }}$ day, in LD neonates hadn't any change comparing with control group, while the body weight in MD and HD neonates had a significant decrease as compared with control group (Table $3 \&$ Fig. 3).

Table 3: Effect of Se NPs on body weight of neonate at the $1^{\text {st }}, 7^{\text {th }}$ and $14^{\text {th }}$ of lactation

\begin{tabular}{|c||c||c||c||}
\hline Group & $\begin{array}{c}\text { Average body wt. of } \\
\text { neonates (g) } \\
\mathbf{1}^{\text {st }} \text { day of lactation }\end{array}$ & $\begin{array}{c}\text { Average body wt. of } \\
\text { neonates (g) } \\
\mathbf{7}^{\text {th }} \text { day of lactation }\end{array}$ & $\begin{array}{c}\text { Average body wt. of } \\
\text { neonates (g) } \\
\mathbf{1 4}^{\text {th }} \text { day of lactation. }\end{array}$ \\
\hline \hline NG & $5.78 \pm 0.10$ & $9.48 \pm 0.13$ & $15.83 \pm 0.28$ \\
\hline \hline LD & $5.90 \pm 0.04$ & $9.80 \pm 0.06$ & $15.98 \pm 0.12$ \\
\cline { 3 - 4 } & $5.55 \pm 0.11$ & $8.40 \pm 0.15^{* * a} \mathrm{a}, \mathrm{b}$ & $14.54 \pm 0.05 * * a, b$ \\
\hline MD & $5.41 \pm 0.07$ & $7.91 \pm 0.03 * * a, b, c$ & $13.12 \pm 0.07 * * a, b, c$ \\
\hline
\end{tabular}

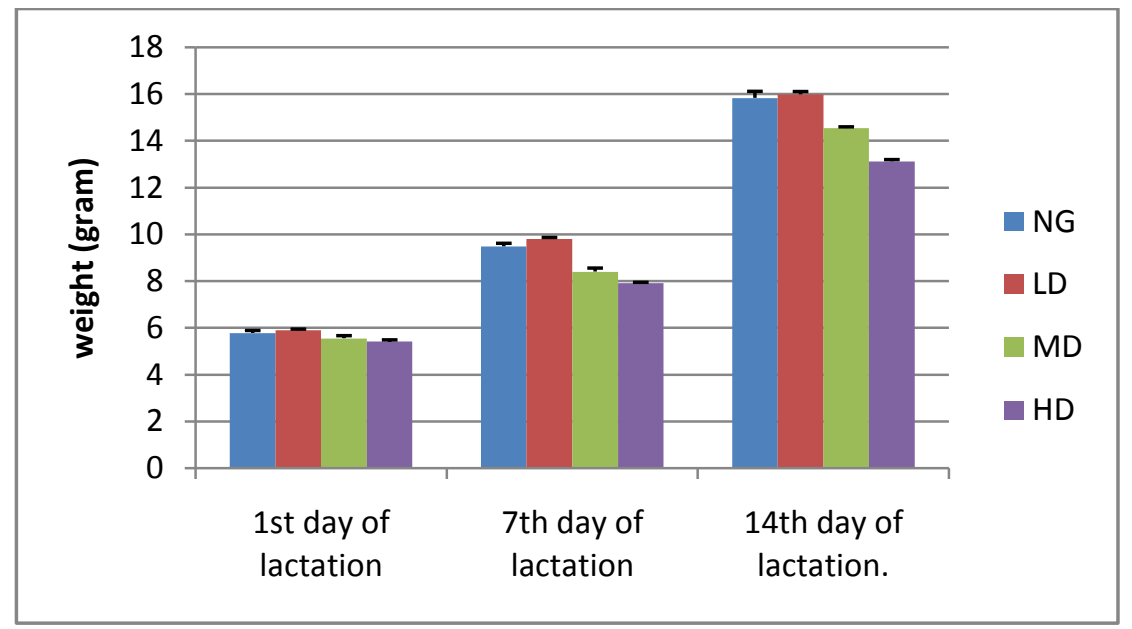

Fig. 3: Effect of Se NPs on Neonate body weight at the $1^{\text {st }}, 7^{\text {th }}$ and $14^{\text {th }}$ of Lactation

Sunde et al. (2009) showed that no effect of dietary Se level on body mass on the weanling mice fed $0,0.05$ and $0.2 \mu \mathrm{g}$ $\mathrm{Se} / \mathrm{g}$ diet, after 35 days.Also, Raines et al .(2011) reported that Male weanling ratsweresupplementedwith0to5 $\mu \mathrm{gSe} /$ gdietfor28dayandweighedbi-weekly. rats fed $5 \mu \mathrm{g} \mathrm{Se} / \mathrm{g}$ diet had significantly lower body weight as compared to all other diet groups. 


\section{Lamiaa E. M. Deef et al.}

\section{1 . Biochemistry Changes}

\subsubsection{Effect of Se NPs on Liver enzyme}

The major characteristics of liver function is Liver enzyme activities, According to (Table 4) for mothers and neonates a significant increase in ALT\& AST. These results further demonstrate that Se NPs cause liver damage that confirms the morphological changes were caused by apoptosis.

Table 4: Effect of Se NPs on Mothers and Neonates Biochemical Markers

\begin{tabular}{|c|c|c|c|c|}
\hline Parameters & $\overline{\mathrm{NG}}$ & $\overline{\text { LG }}$ & MG & HG \\
\hline ALT u/L(Mother ) & $26.00 \pm 4.93$ & $29.66 \pm 4.84$ & $63.66 \pm 3.28 * * a, b$ & $63.66 \pm 4.66 * * a, b$ \\
\hline AST u/L(Mother ) & $82.66 \pm 4.48$ & $77.33 \pm 6.35$ & $122.66 \pm 5.81 * * a, b$ & $148.33 \pm 10.03 * * a, b$ \\
\hline ALT u/L (neonates) & $17.66 \pm 2.60$ & $20.66 \pm 2.18$ & $29.30 \pm 2.16 * * a, b$ & $39.33 \pm 4.84 * * a, b, c$ \\
\hline AST u/L(neonates) & $56.33 \pm 4.66$ & $57.66 \pm 2.84$ & $65.00 \pm 2.51$ & $72.00 \pm 3.21 * * a, b$ \\
\hline
\end{tabular}

The present results is in agreement with those of Hasegawa et al. (1996) who reported that ALT and AST was increased significantly in $5 \mu \mathrm{g} \mathrm{Se} / \mathrm{g}$ diet rats as compared to all other diet groups, and was approximately twice that of Se-adequate $(0.24 \mu \mathrm{g} \mathrm{Se} / \mathrm{g})$ rats in his experiment.

\subsection{Effect of Se NPs on Antioxidant levels (Glutathione Peroxidase)}

In the current study, Table (5) represents the mother rats GPx activity for each group. GPx level in LD was $(10.97 \pm 0.18)$ higher than GPx activity
$(10.69 \pm 0.09)$ found in control group, indicating improvement in redox status especially in level of GPX activity. However, GPx levels in mothers of MD and HD were $8.10 \pm 0.30$ and 4.46 \pm 0.29 , respectively, decreased significantly in comparing with control group, indicating elevating oxidative stress in our experimental rats due to toxicant dose of Selenium (Fig. 4).

For neonate the GPX levels of MD and HD were 8.20 \pm 0.35 and $7.30 \pm 0.45$, respectively, non-significant decreased in comparing with control group $(8.70 \pm 0.58)$.

Table 5: Effect of Se NPs on Mothers and Neonates Biochemical Markers

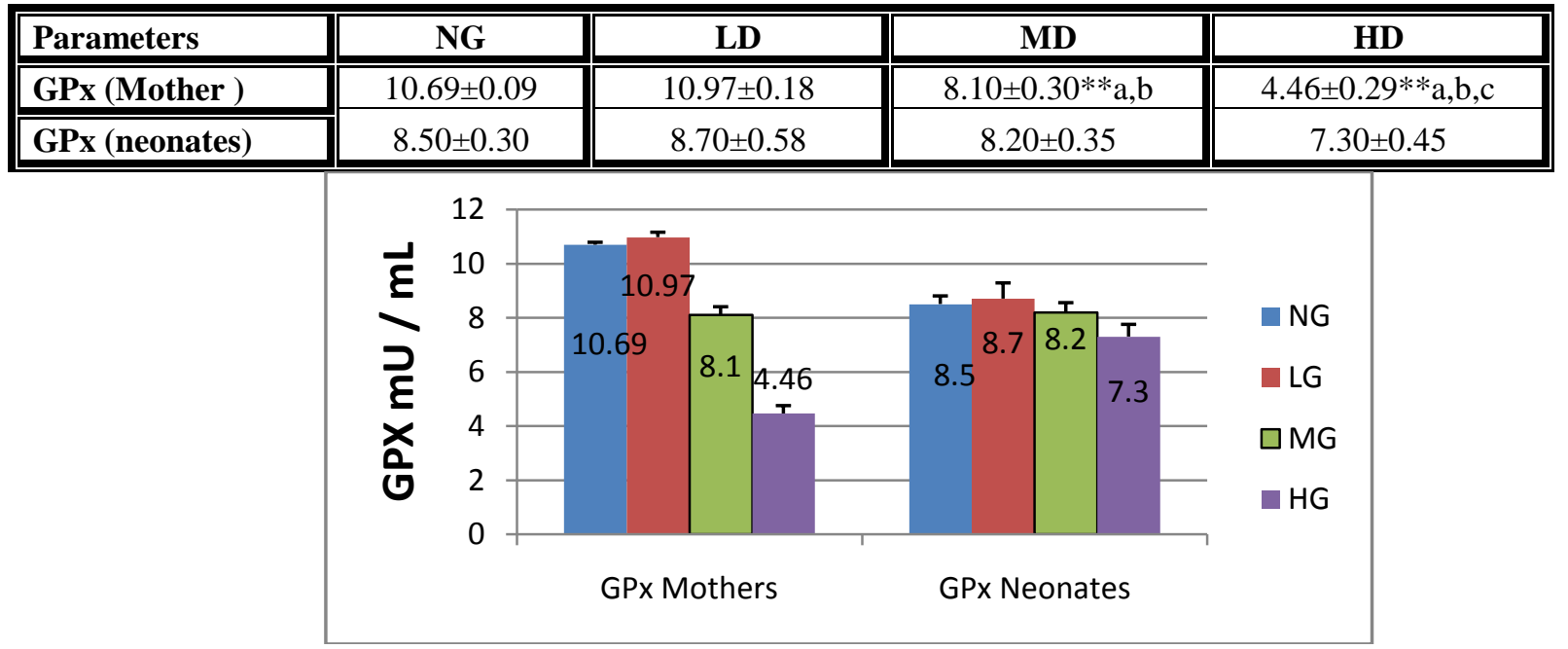

Fig. 4: Effect of Se NPs on GPX level. 


\section{Toxicity of selenium nanoparticles on the development of rat neonates}

Wang et al. (2007) reported that Se NPs present excellent biological activity and low toxicity compared with selenocyanates, selenites, and selenocysteine. The level of Gpx in the present results was in agreement with Raines et al. (2011) who found that Gpx activity was not further increased by super nutritional Se, and slightly decreased by $5 \mu \mathrm{g} \mathrm{Se} / \mathrm{g}$ as compared to the Se adequate diet $(0.24 \mu \mathrm{g} \mathrm{Se} / \mathrm{g})$. These changes may be varying of doses of Se. Indeed, Gpx results were nearly similar to Zhang et al. (2013). In his study, Gpx level of mice treated with an excess dose of Se orally was decreased compared to those in the Se adequate group.

\subsection{Histological Changes}

\subsubsection{Effect of Se NPs on the structure of} Neonates liver by Light Microscopy

In the present investigation, it was observed that the structure of liver in control neonates group was normal where hepatic cords arranged normally around central vein (Fig. 5 A \& B).In neonates group received moderate and high dose blood vessels were congested and there was mild degeneration in hepatocytes (Fig. 5 C \& D).

He et al. (2014) reported that histopathological changes were observed in the groups given doses of 2.0, 4.0, and 8.0 $\mathrm{mg} \mathrm{Se} / \mathrm{kg}$-bw, particularly in the $8.0 \mathrm{mg}$ $\mathrm{Se} / \mathrm{kg}$-bw group. Liver mainly consisted of focal hepatocyte necrosis and degeneration (He et al., 2014).

Under selenium toxicity Wang et al., (2007) found that of selenium caused liver injury. In addition to comparing with normal liver architecture SeMet caused irreversible and serious pathological change in the form of pyknosis, that comes before necrosis and apoptosis, whereas Nano-Se caused degeneration, which belongs to reversible and moderate pathological change.

Jia et al. (2005) noted that the major changes observed were different degrees of vacuolar degeneration of liver cells at higher doses of Se, while mild degeneration of liver cells was observed consuming lower $\mathrm{Se}$ doses.

On the other hand, in control neonates group have normal seminiferous tubules and interstitial tissue in testes sections (Fig. 6, A \& B). In contrast there was marked interstitial edema (black arrows), vacuolation in tubular epithelium (red arrows) and desquamation of tubular epithelium (yellow arrows) in both Neonates group received moderate and high doses (Fig. $6 \mathrm{C} \& \mathrm{D}$ ).

Kaur et al. (2000) reported that excess of dietary Se caused dose-timedependent increase in number of morphologically abnormal spermatozoa .The weight of the testis of rats treated with 8.0 $\mathrm{mg}$ Se/kg-bw decreased significantly and atrophied seminiferous tubules were observed. Also Histopathological studies of the testes and caudal epididymis have revealed that Se-rich diets cause disintegration of cellular associations in the seminiferous tubules.

\subsubsection{Effect of Se NPs on ovary and testes by Electron Microscopy}

Instead, both normal control group and group received low dose and have a normal ovary distribution patterns components with Normal structure of Surface epithelium, Cortex and inner medullary region and Primordial follicles defined as an oocyte surrounded by a layer of squamous (flattened) granulosa cells with large eccentric nucleus mainly found at periphery, Primary follicles possessed an oocyte surrounded by a single layer of cuboidal granulosa cells and the Secondary follicles were surrounded by more than one layer of cuboidal granulose (Fig. 7 A and B).

At moderate group (MD) the ovary primordial follicle is slightly deviated from the control group squamous epithelium and 


\section{Lamiaa E. M. Deef et al.}

is not normal and the position of oocyte is disturbed. Oocytes are also not in normal shape and reduced in size, Primary follicles are compact, compressed, shows disorder in arrangement of granulosacells (Fig. 7 C).

The extent of pathological changes in the ovarian tissues shows in Figure (7D), where ovary had more severity damage where, the surface epithelium was highly damaged and detached and few parts absent. The cortical area was filled with numerous primordial follicles extends to the medullary region, however, most of them were distorted, exhibits disintegrated nuclei with damaged squamous epithelium. There few secondary follicles were damaged.

The follicles are the functional unit of the ovary. They are present within the ovary in various stages of development. The primordial follicle develops into the primary follicle, which consists of a primary oocyte surrounded by a single layer of more cuboidal granulosa cells. This follicle develops into the preantral follicle, which consists of a single oocyte surrounded by at least two layers of granulosa cells and a newly formed theca cell layer encasing the oocyte and granulosa cells. Any toxicant can affect follicle numbers, follicle growth and development (Hood, 2016).

The ultra-structural characteristics of the investigated ovary of 14 day old albino rat control group and group of low dose showed normal typical Gonocytes $(\mathrm{G})$ which was elongating and reaching the basement membrane. And $7 \mathrm{~B}$ The cytoplasm in case of division due to its activity represent a transient and finite phase of development involves successive phases of proliferation and differentiation for the first spermatogenic wave (Fig. 8 A\& B).

At moderate dose group, Gonocytes have vacuolization in its cytoplasm (\#), Multinucleated gonocytes and Early apoptosis of gonocytes were chromatin beginning to condense and Swollen mitochondria $(\mathrm{M})$, with the degeneration or loss of cristae in these phases, cytoplasmic organelles still appear normal (Fig. 8 C).

Figure $(8$ D) show typical nuclear condensation that represent advanced states of apoptosis of gonocytes (G) were condensation and margination of nuclear chromatin around the nuclear periphery occur. Vacuolated cytoplasm, electron-dense bodies, concentric lamellar formations and irregular shaped nuclei till complete degeneration.

Transmission electron micrographs of Primordial follicle of ovary are described in Figure (.9 A \& B) control group and low dose group showing: Normal primordial follicle with typical flattened granulosa cells (GC), the dictyate oocyte with its germinal vesicle (GV) or nucleus, all the mitochondria (M) normal and gathered at one pole of the $\mathrm{GV}$, and basal lamina (BL), but in Figure (9 C \& D)moderate dose and high dose, respectively, the shape of most of the Primordial follicles distorted, reduced in size and lost their normal distribution and It exhibits oval nuclei losing their original round shape with damaged squamous epithelium, it is altered giving oval to squeezing appearance to follicular structure, with slightly hypertrophied and dispersed granulosa cells. Vacuolation and irregular shape of oocyte is hallmark beside that There is increase in the number of damage follicles.

As show in Figure (10 A \& B) preantral secondary follicle of ovary at PND 14 albino rat of varies treatment doses of selenium nanoparticles are described. The control group and low dose group had : A typical healthy secondary follicle contains a fully grown oocyte $(\mathrm{O})$, The granulosa cell processes traversing surrounded by the welldeveloped regular zonapellucida, layers of granulosa cells (GC), a basal lamina (BL), and developing and distinct separation between granulosa cells. Also Oocyte 


\section{Toxicity of selenium nanoparticles on the development of rat neonates}

granulosa cells in a preantral secondary follicle. The zonapellucida (ZP) makes small gap junctions with the oocyte plasma membrane. Larger gap junctions are evident between coronas radiate.

As seen in Figure 10 (C \& D) shape of preantral secondary follicles in Normal is altered and looks like shrined or suppressed and it became oblong and blunt in shape. The granulosa cells severely affected, it clumped compactly and attached to each other, the numbers of atretic follicles slightly increased showing pyknosis in
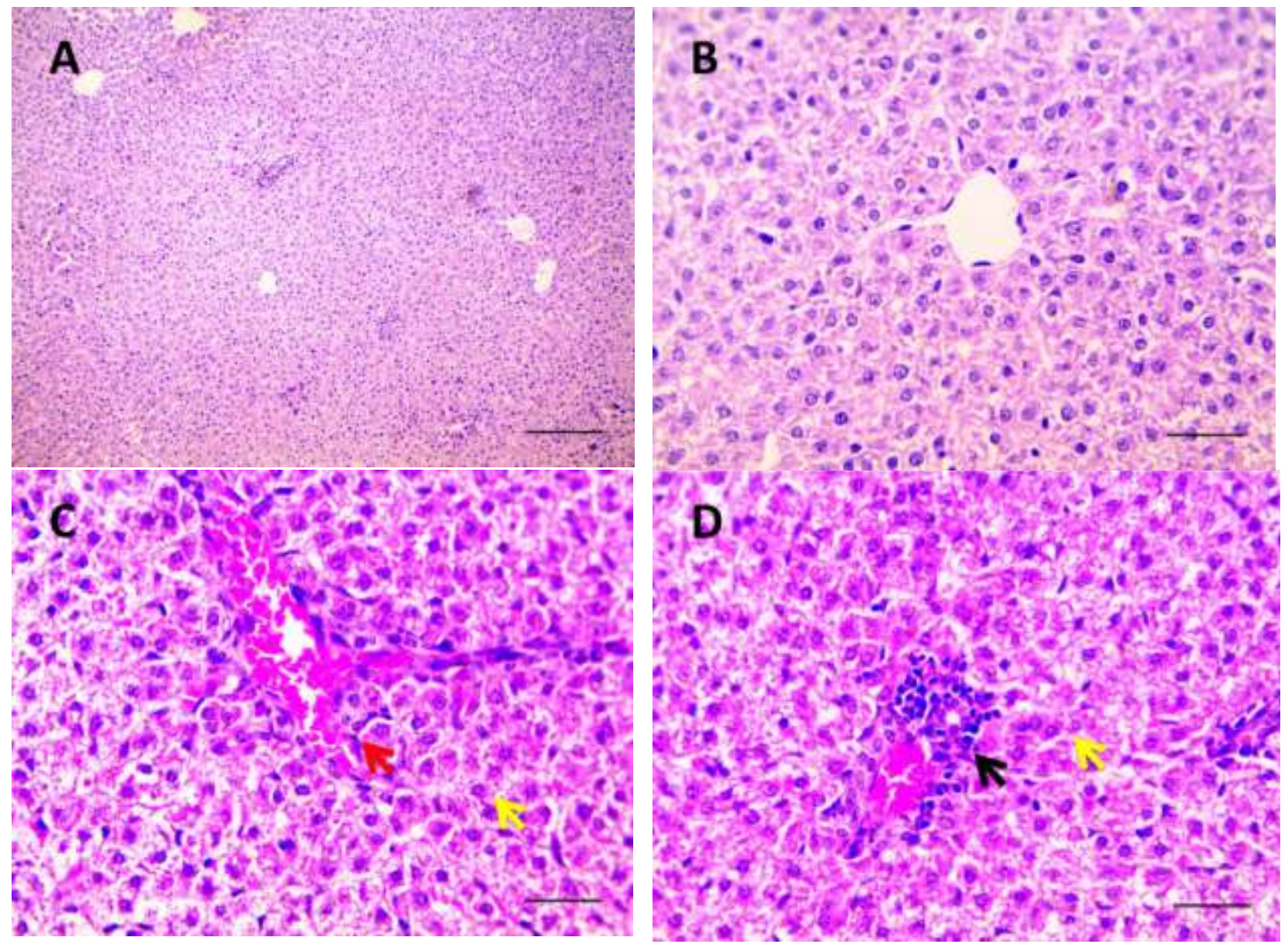

Fig. (5): Microscopic pictures of H\&E stained Liver sections of 14 old age neonates for the four groups $(\mathrm{A}=\mathrm{NG}, \mathrm{B}=\mathrm{LD}, \mathrm{C}=\mathrm{MD}$ and $\mathrm{D}=\mathrm{HD})$. (A) X: 100 and (B,C,D) X: 400 Bar 50. 
Lamiaa E. M. Deef $e t a l$.
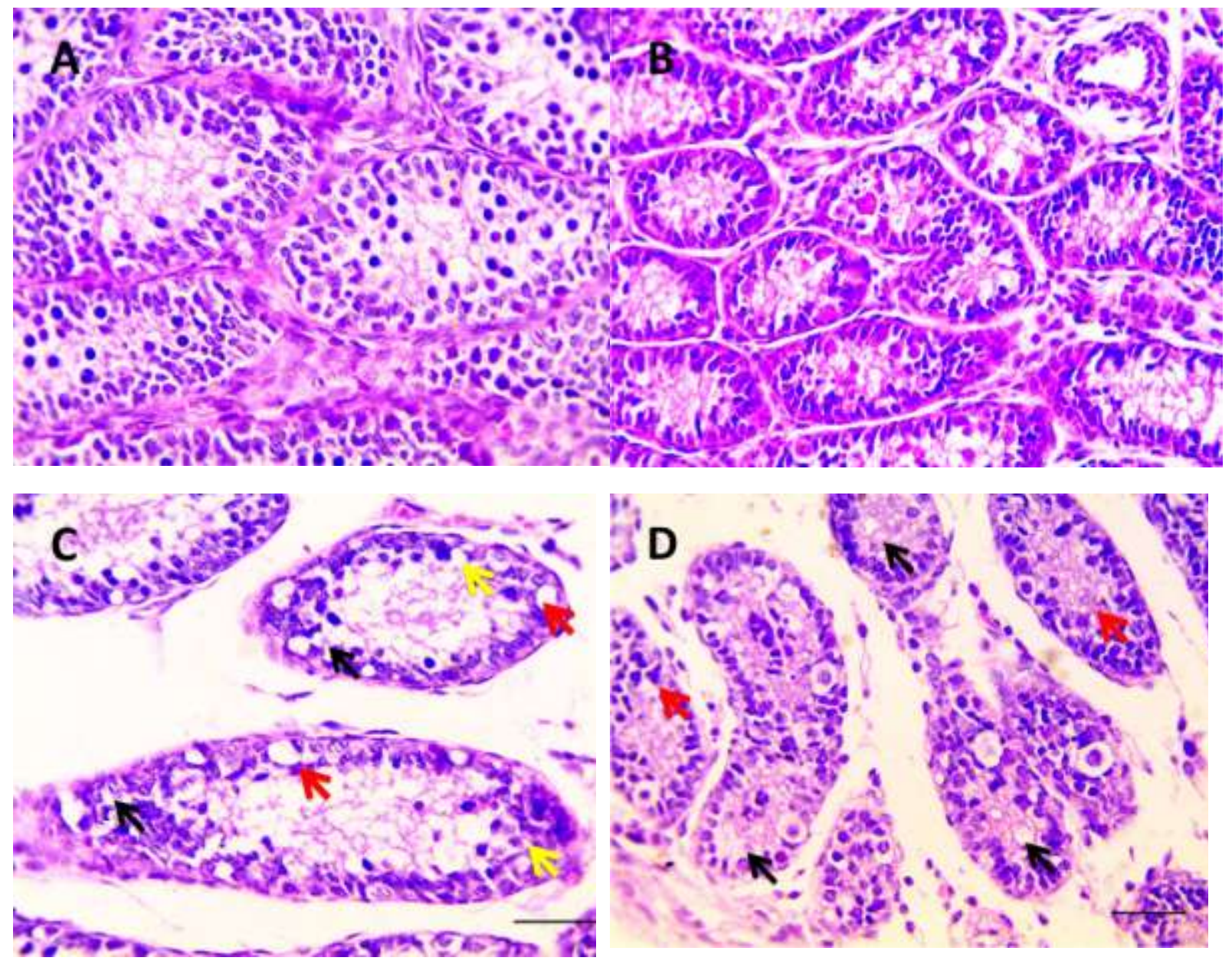

Fig (6): Microscopic pictures of $H \& E$ stained testes sections of 14 old age neonates for the four groups ( $A=N G, B=L D, C=M D$ and $D=H D)$.X:400 Bar 50. 
Toxicity of selenium nanoparticles on the development of rat neonates

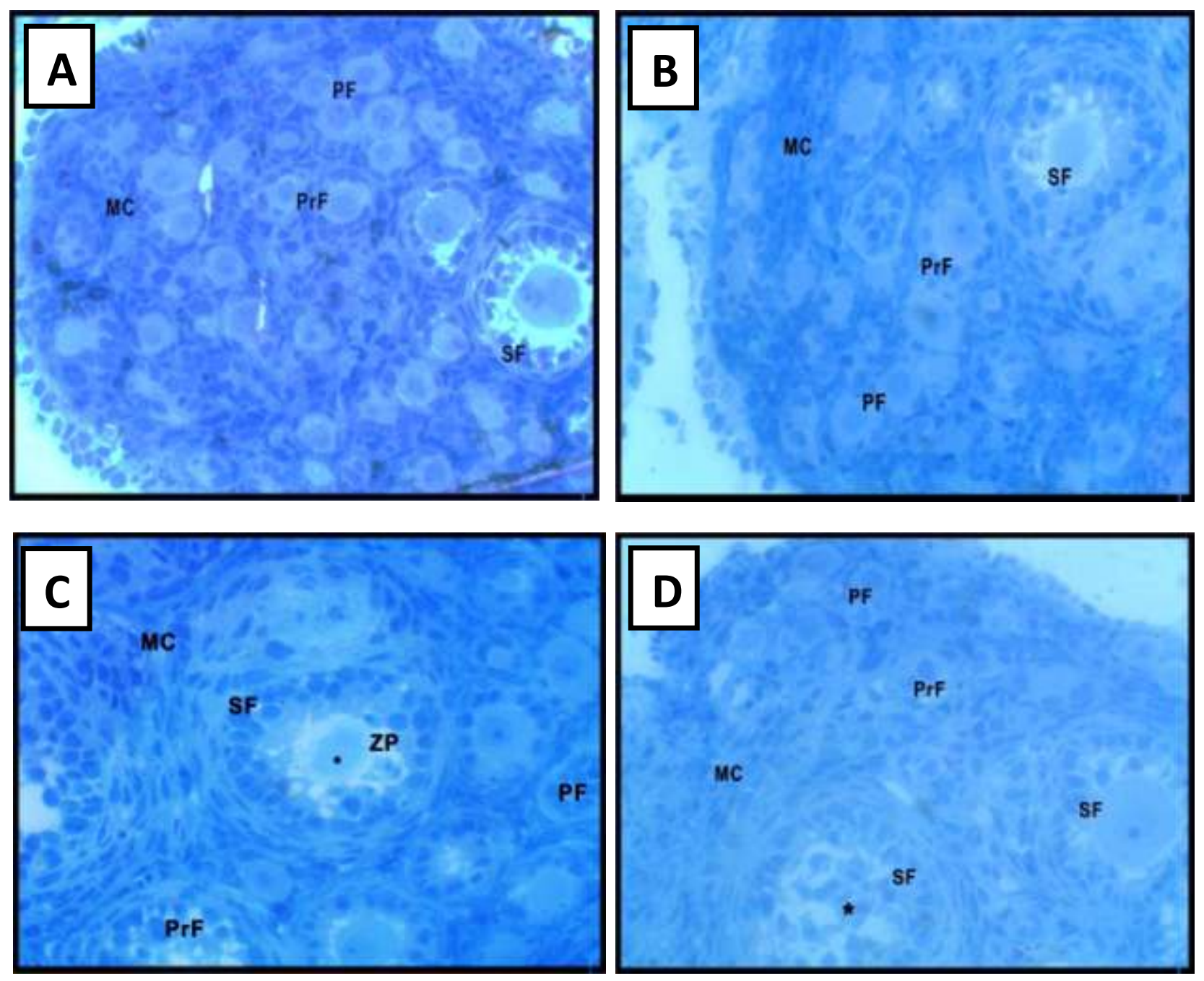

Fig. (7): Microscopic pictures of Semi thin Section of ovariesstained with toluidine blue of 14 old age neonates for the four groups $(\mathrm{A}=\mathrm{NG}, \mathrm{B}=\mathrm{LD}, \mathrm{C}=\mathrm{MD}$ and $\mathrm{D}=\mathrm{HD}) . \mathrm{X}: 400$ Bar 50 . 
Lamiaa E. M. Deef et al.

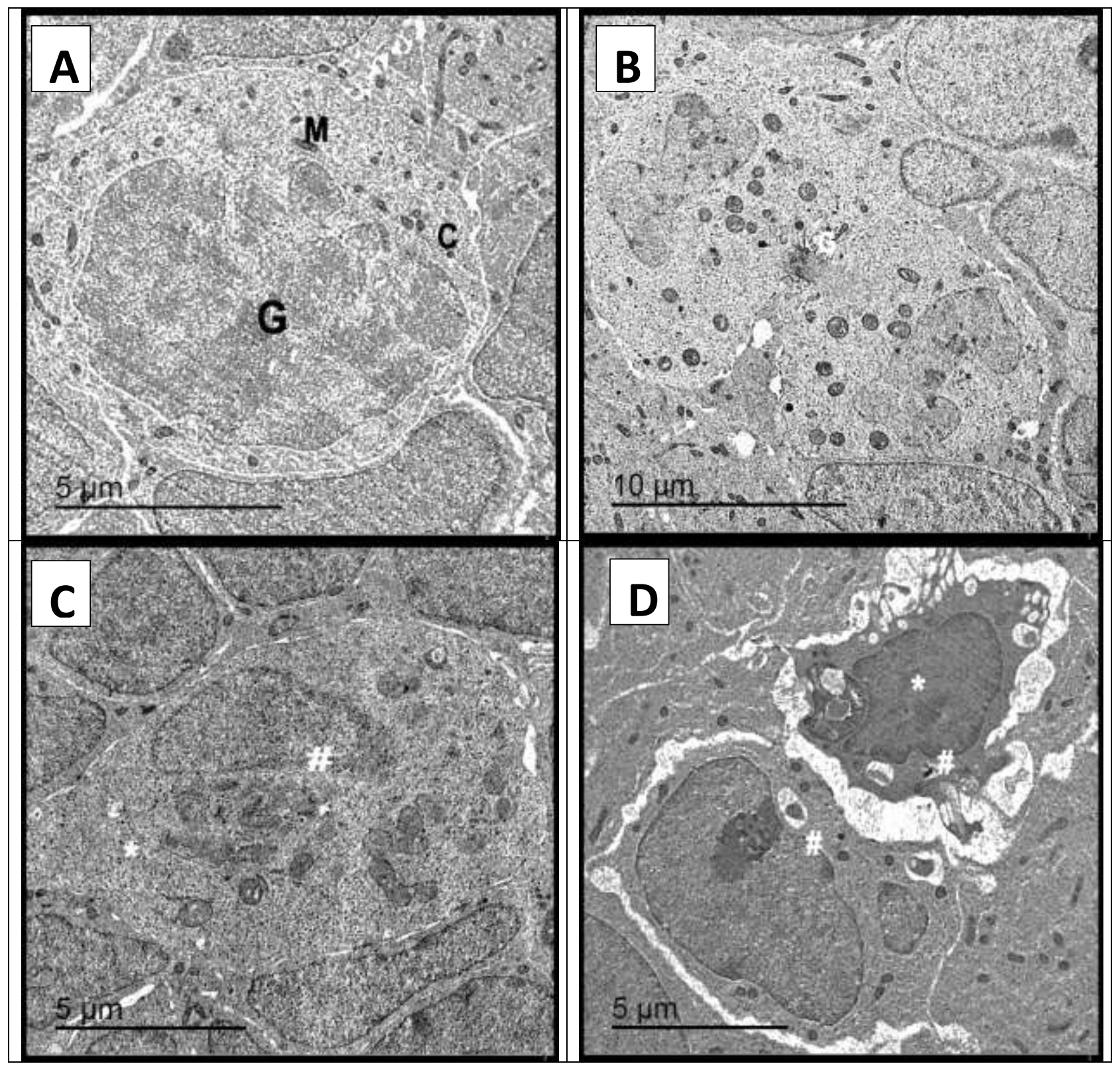

Fig.(8):transmission electron micrograph of 14 day old albino rat control group show: Gonocytes $(\mathrm{G})$, cytoplasm $(\mathrm{C})$ and mitochondria $(\mathrm{M}) .(\mathrm{A}=\mathrm{NG}, \mathrm{B}=\mathrm{LD}, \mathrm{C}=\mathrm{MD}$ and $\mathrm{D}=\mathrm{HD})$. 
Toxicity of selenium nanoparticles on the development of rat neonates
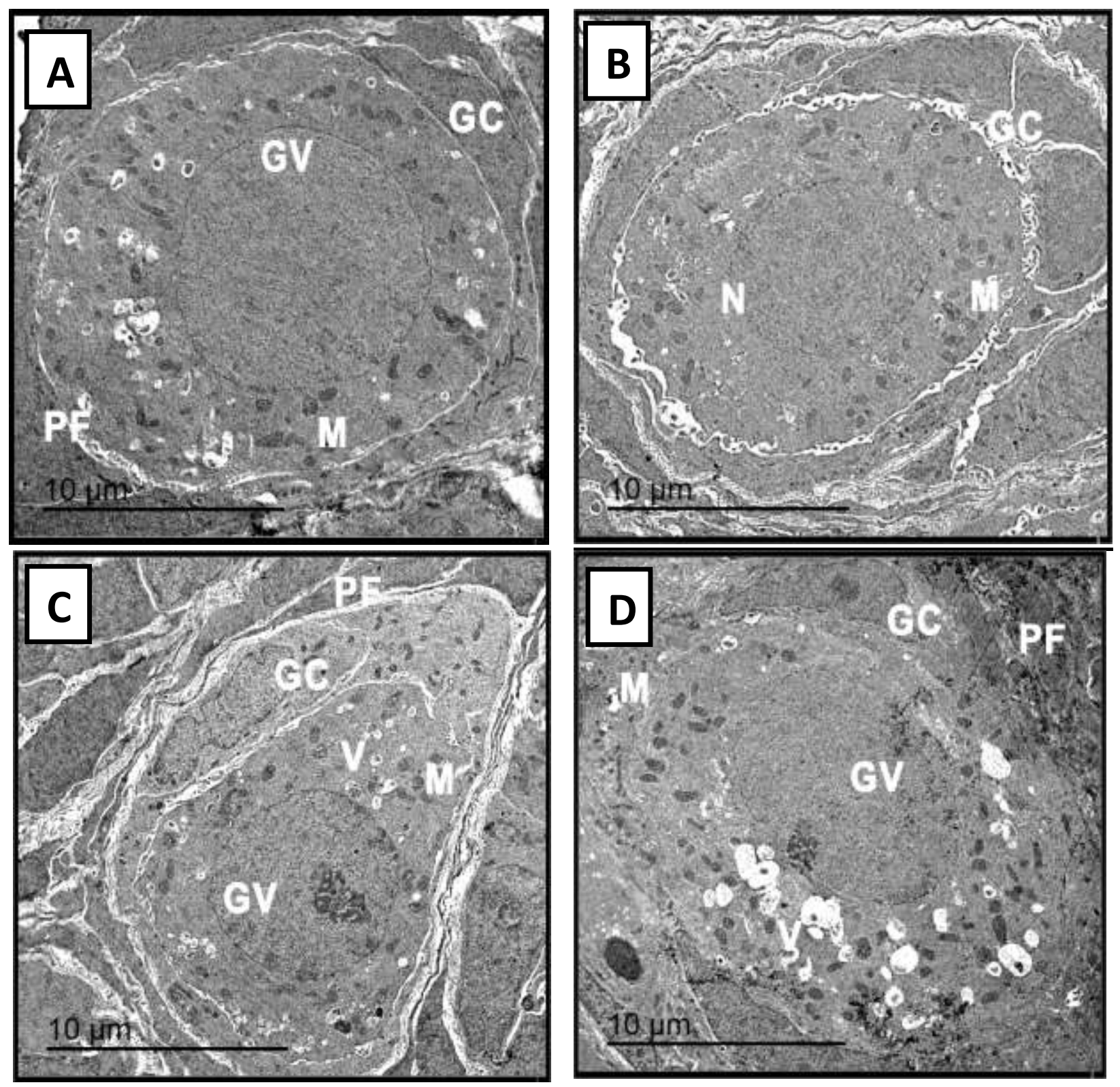

Fig.(9):Transmission electron micrographs of Primordial follicle of ovary at PND 14 albino rat of different treatment doses of selenium nanoparticles described flattened granulosa cells (GC), germinal vesicle (GV) or nucleus, and mitochondria (M). A = Normal group, $\mathrm{B}=$ Low Group, $\mathrm{C}=$ Moderate Group and $\mathrm{D}=$ High group. 

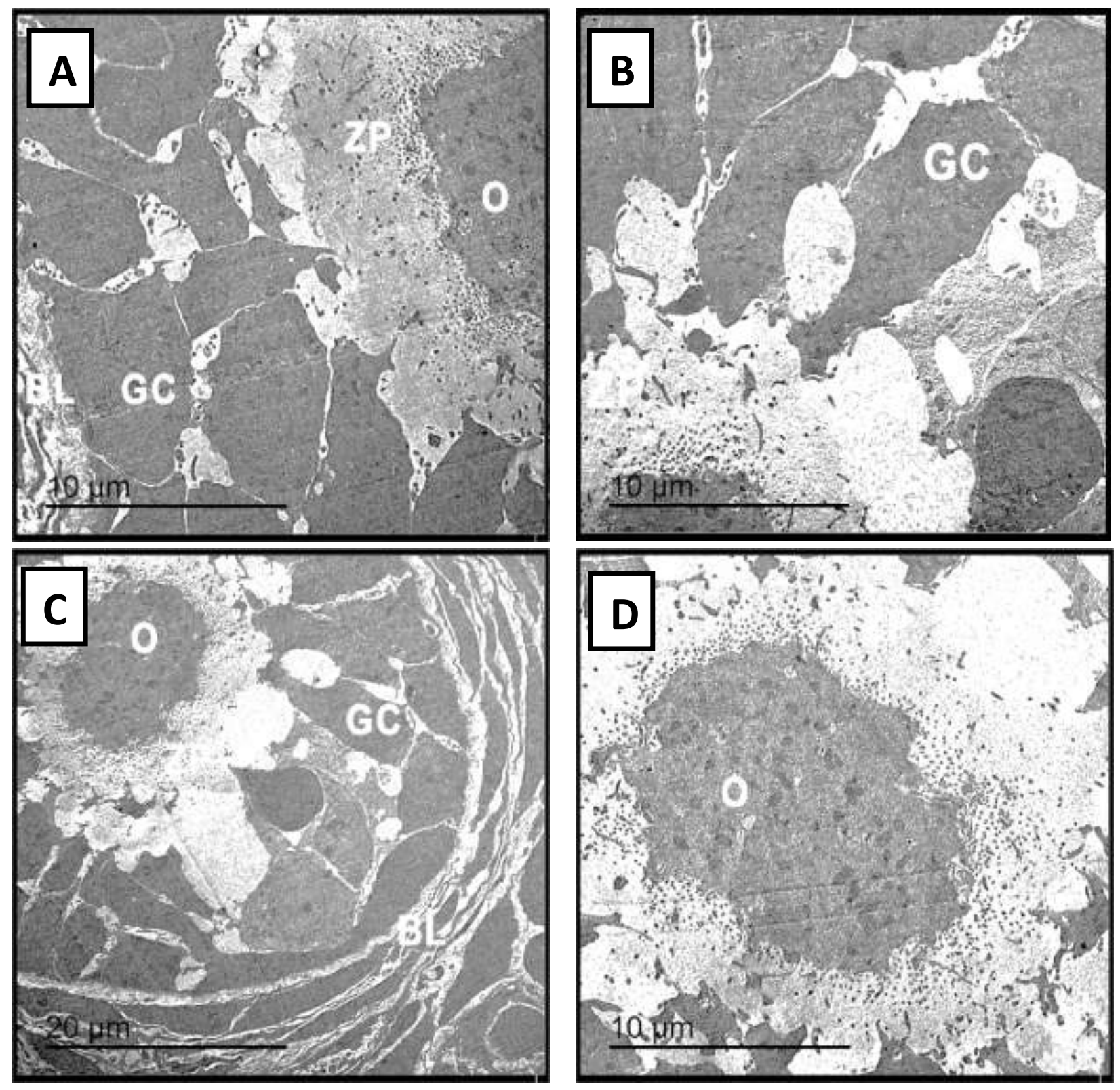

Fig. (10): Transmission electron micrographs of preantral secondary follicles of ovary at PND 14 albino rat of different treatment doses of selenium nanoparticles described. $\mathrm{A}=$ Normal group, $\mathrm{B}=$ Low Group, $\mathrm{C}=$ Moderate Group and D = High group.

\section{CONCLUSION}

In the present study, we found that Se NPs are not toxic at supranutritional levels and may be suitable. They may have a positive effect on both neonate rats health at a dose of $0.5 \mu \mathrm{g} \mathrm{Se} / \mathrm{kg}-\mathrm{bw}$ and in mother rats growth, while the chronic toxicity will be induced by Se NPs greater than $1.7 \mu \mathrm{g}$
Se/kg-bw. More studies are required to get a deep insight into the toxicity mechanism of the Se NPs.

\section{REFERENCES}

ECCLS (1989). Determination of the catalytic activity concentration in serum on L- aspartate 


\section{Toxicity of selenium nanoparticles on the development of rat neonates}

aminotransferase (EC 2.6.1.1, AST)

Clin Chem., 20:204-211.

Banchroft J., Stevens A., and Turner D. Theory and practice of histological techniques. Churchil Livingstone, New York, London, San Francisco, Tokyo, 1996: 129-134.

Cheville, N. and Stasko, J. (2014). Techniques in electron microscopy of animal tissue. Veterinary Pathol., 51(1): 28-41.

Hood, R.D. (2016). Developmental and reproductive toxicology: a practical approach: CRC press.

Hosnedlova, B.; Kepinska, M.; Skalickova, S.; Fernandez, C.; Ruttkay-Nedecky, B.; Peng, Q. and Zidkova J. (2018). Nano-selenium and its nanomedicine applications: A critical review. Int. J. Nanomedicine, 13: 2107.

Hasegawa T.; Mihara M.; Nakamuro K., and Sayato Y. (1996). Mechanisms of selenium methylation and toxicity in mice treated with selenocystine. Archives Toxicol., 71(1-2): 31-38.

He Y; Chen S.; Liu Z.; Cheng C.; Li H., and Wang M. (2014). Toxicity of selenium nanoparticles in male Sprague-Dawley rats at supranutritional and nonlethal levels. Life sciences, 115(1-2): 44-51.

Jia X.; Li N. and Chen J. (2005). A subchronic toxicity study of elemental Nano-Se in SpragueDawley rats. Life sciences, 76(17): 1989-2003.

Kaur R., and Kaur K. (2000). Effects of dietary selenium (SE) on morphology of testis and cauda epididymis in rats. Ind. J. Physiol. Pharmacol., 44(3): 265-272.

Koller, L. and Exon, J. (1986). The two faces of selenium-deficiency and toxicity--are similar in animals and man. Canad. J. Veterinary Res., 50(3): 297.
Misra, S.; Boylan, M.; Selvam, A.; Spallholz, J. and Björnstedt, M. (2015). Redox-active selenium compounds-From toxicity and cell death to cancer treatment. A New Era in Oncology, 7(5) : 3536-3556.

Morris, J.S. and Crane, S.B. (2013). Selenium toxicity from a misformulated dietary supplement, adverse health effects, and the temporal response. Nail Biologic Monitor., 5(4): 1024-1057.

Nogueira, C.W. and Rocha, J.B. (2011). Toxicology and pharmacology of selenium: emphasis on synthetic organoselenium compounds. Archives Toxicol., 85(11): 13131359.

Ostadalova, I. (2012). Biological effects of selenium compounds with a particular attention to the ontogenetic development, 61: S19.

Paglia, D.E. and Valentine, W.N. (1967). Studies on the quantitative and qualitative characterization of erythrocyte glutathione peroxidase. J. Laboratory and Clinical Medicine, 70(1): 158-169.

Raines, A.M. and Sunde, R.A. (2011). Selenium toxicity but not deficient or super-nutritional selenium status vastly alters the transcriptome in rodents. BMC genomics, 12(1), 26.

UNECEGlobally Harmonized System of Classification and Labelling of Chemicals (GHS)2013;available onhttp://www.unece.org/trans/danger /publi/ghs/ghs_rev05/05files_e.html

Vekariya, K. K., Kaur, J., and Tikoo, K. (2012). ER $\alpha$ signaling imparts chemotherapeutic selectivity to selenium nanoparticles in breast cancer. Nanomedicine: Nanotechnology, Biology and Medicine; 8(7): 1125-1132. 


\section{Lamiaa E. M. Deef et al.}

Weiss, S. L., Evenson, J. K., Thompson, K. M., and Sunde, R. A. (1997). Dietary selenium regulation of glutathione peroxidase mRNA and other selenium-dependent parameters in male rats. J. Nutr. Biochem.,8(2): 8591.

Wang, H., Zhang, J., and Yu, H. (2007). Elemental selenium at nano size possesses lower toxicity without compromising the fundamental effect on selenoenzymes: comparison with selenomethionine in mice. Free Radical Biology and Medicine; 42(10): 1524-1533.

Wang, N.; Tan, H.Y.; Li, S.; Xu, Y.; Guo, W. and Feng, Y. (2017). Supplementation of micronutrient selenium in metabolic diseases: its role as an antioxidant. Oxidative medicine and cellular longevity, Volume 2017, at: https://doi.org/10.1155/2017/7478523 Young, D.S. (1990). Effects of drugs on clinical laboratory tests. Washington, DC: American Association for Clinical Chemistry,

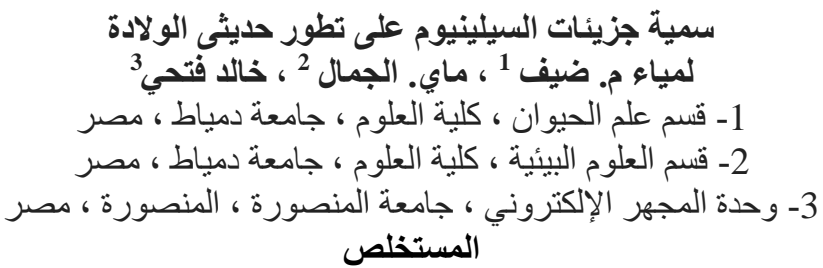

الهدف من هذه الدر اسة تقييم آثار النانو سيلينيو على بعض انسجة للأعضاء التناسلية (للذكور وللإناث) ، وكذللك لتحديد

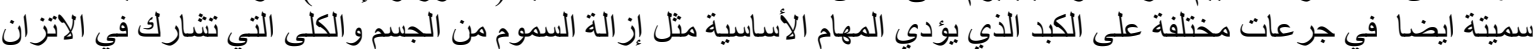

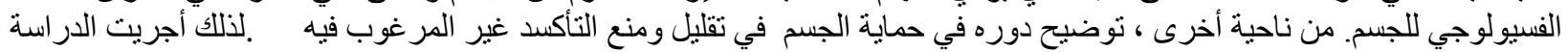

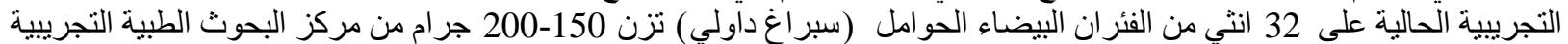

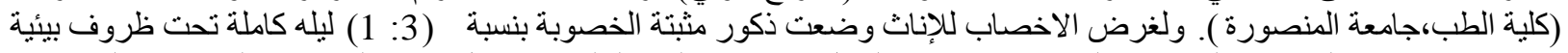

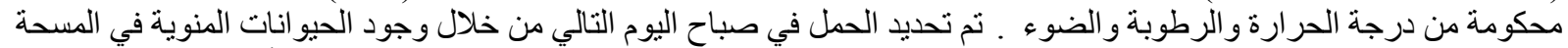

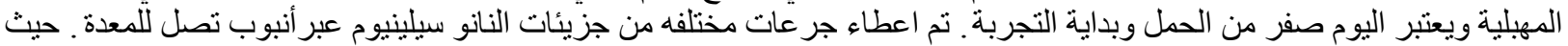

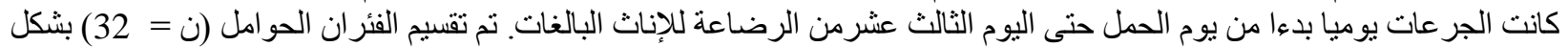

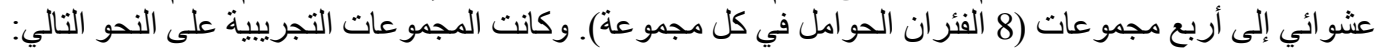

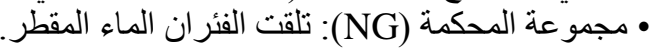

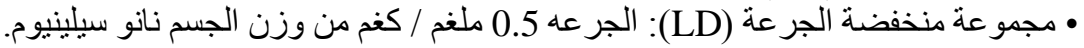

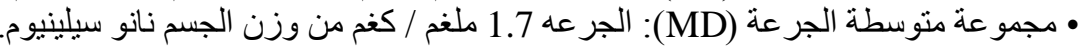

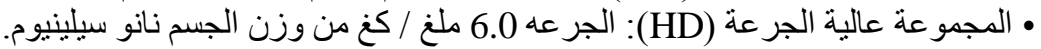

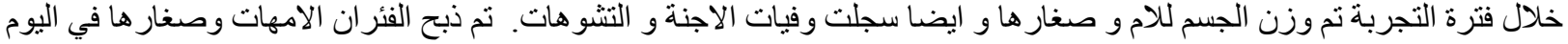

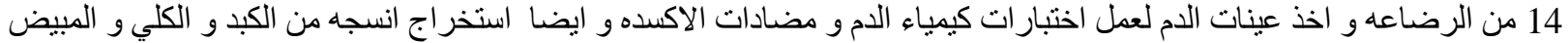

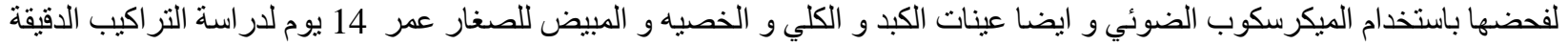

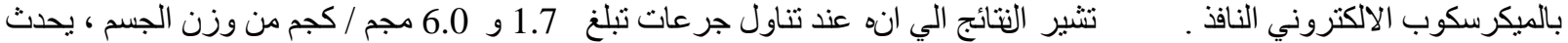

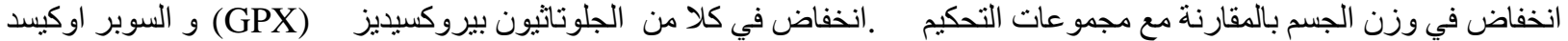

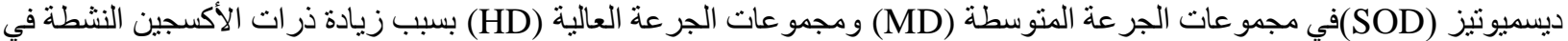

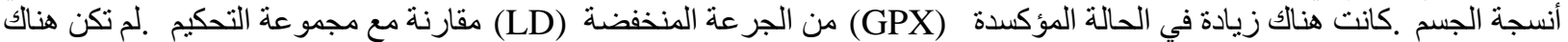

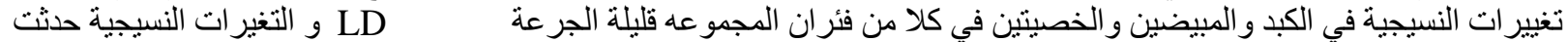

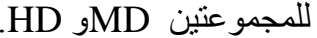

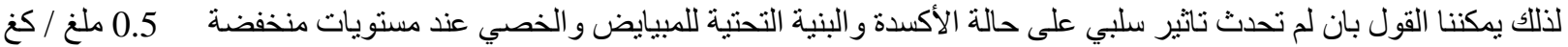

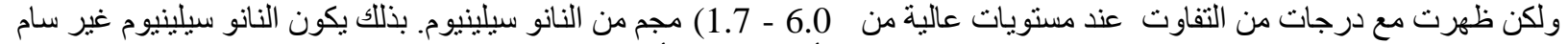

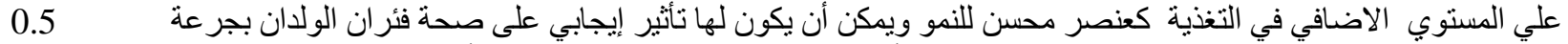

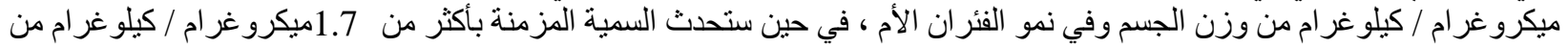

